\title{
compactadoras de placas
}
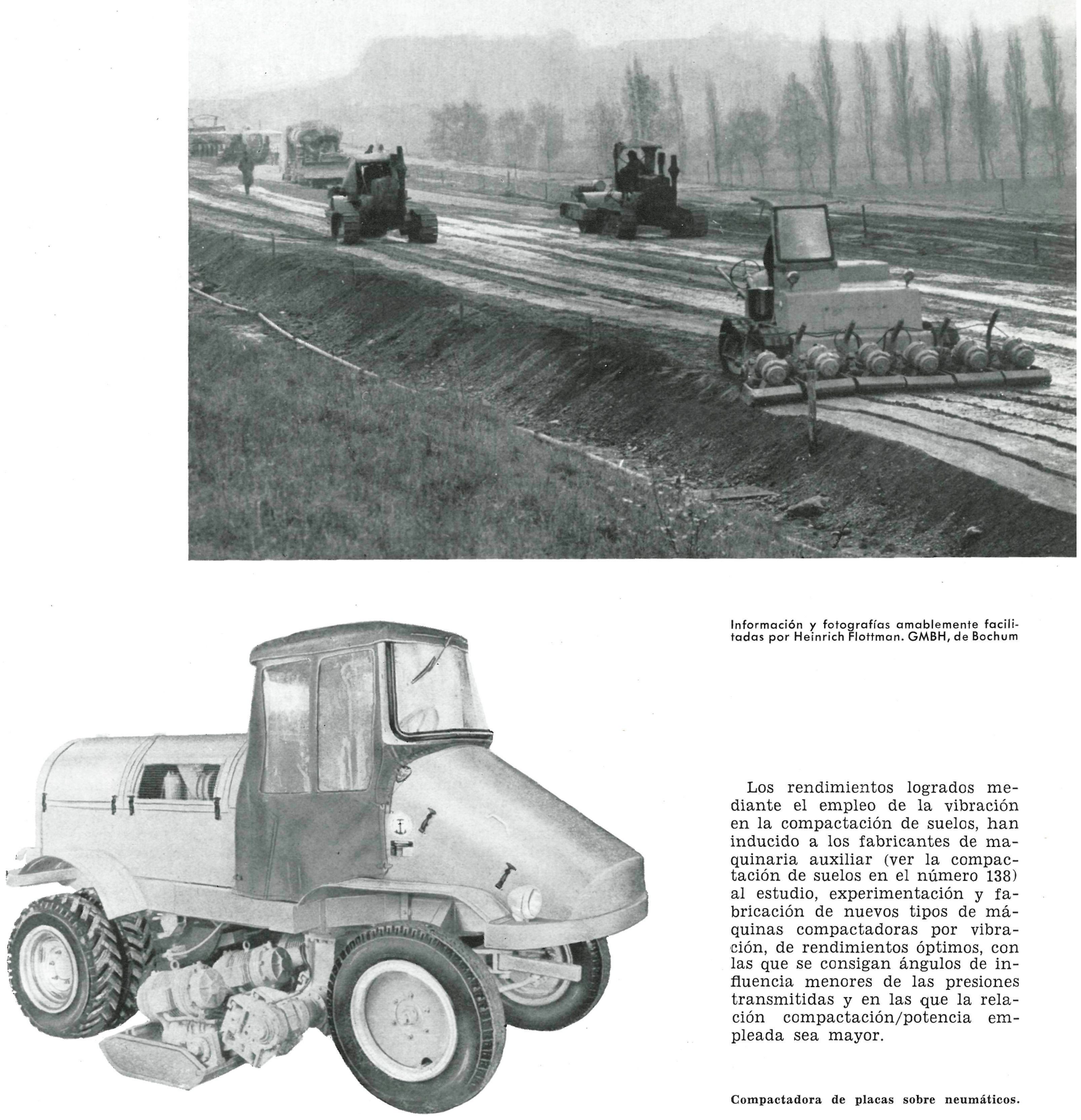

Información y fotografías amablemente facilitadas por Heinrich Flottman. GMBH, de Bochum

Los rendimientos logrados mediante el empleo de la vibración en la compactación de suelos, han inducido a los fabricantes de maquinaria auxiliar (ver la compactación de suelos en el número 138) al estudio, experimentación y fabricación de nuevos tipos de máquinas compactadoras por vibración, de rendimientos óptimos, con las que se consigan ángulos de influencia menores de las presiones transmitidas y en las que la relación compactación/potencia empleada sea mayor.

Compactadora de placas sobre neumáticos. 


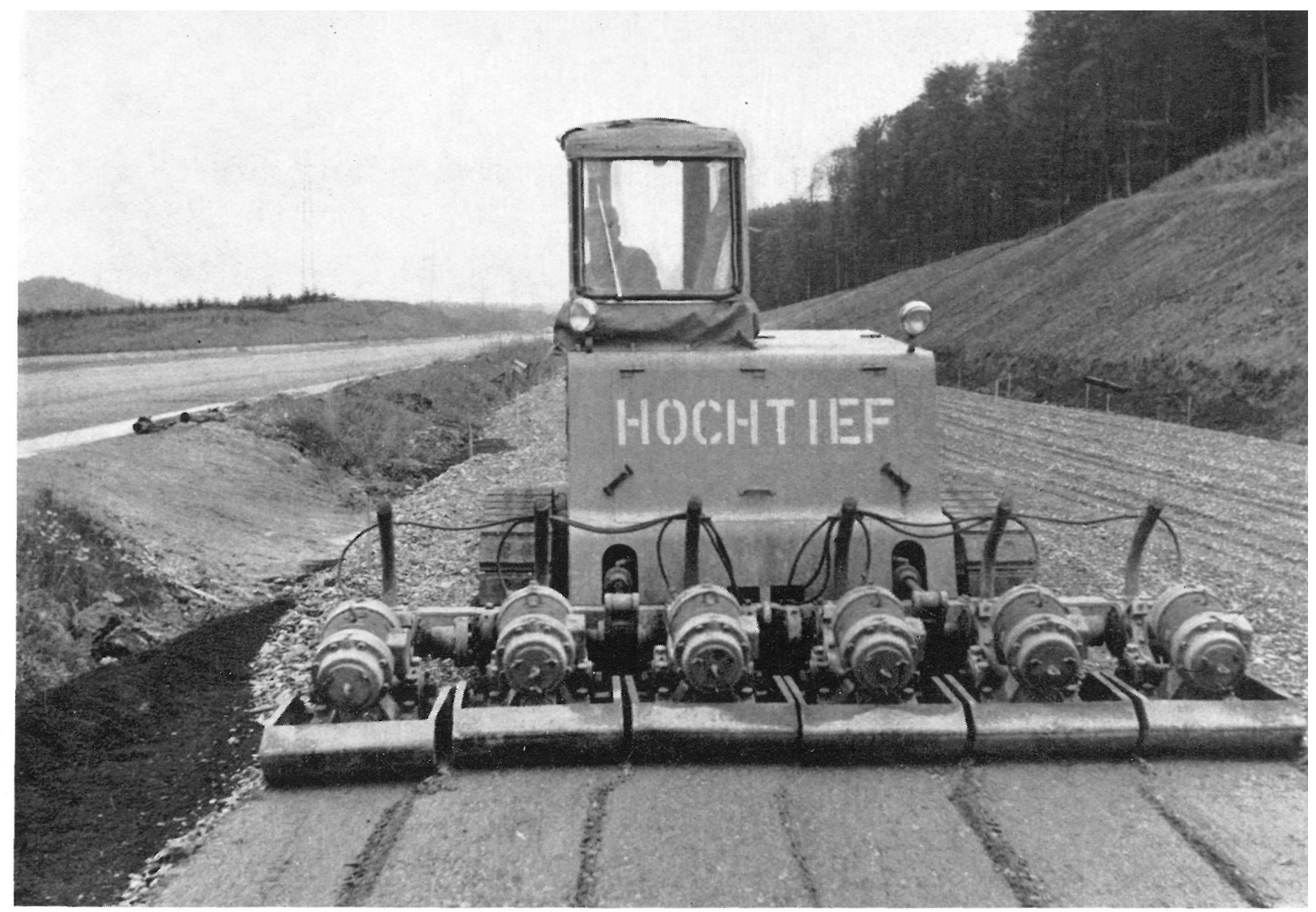

Compactadora de placas Vibrotek R-42.

Entre estos nuevos tipos de maquinaria se encuentran las compactadoras de placas, normalmente vehículos automotrices sobre orugas y provistos de placas vibradoras especialmente diseñadas y adaptadas para efectuar la compactación de zonas de extensión variable y distintas características.

En casi todos los tipos la vibración de las placas se consigue mediante el giro de masas excéntricas, de forma que la componente vertical de las oscilaciones circulares sea transmitida al suelo de la forma más completa posible, siendo mínimas las componentes horizontales.

La fuerza centrífuga es ampliamente variable, mediante el desplazamiento de una de las masas excéntricas con relación a la otra, operación sencilla y fácilmente realizable en corto espacio de tiempo. El montaje de las excéntricas en el propio eje de los motores eléctricos de accionamiento, permite un mejor aprovechamiento de la potencia al evitar el empleo de transmisiones.

El accionamiento de los motores eléctricos es independiente, de forma que sea factible el arranque individual con un menor consumo de potencia y la posibilidad de puesta en fuera de servicio de aquellas placas que por las características de la zona de trabajo no deseen utilizarse.

Los sistemas de suspensión de las placas están estudiados en cada máquina de forma que la transmisión práctica de vibraciones al bastidor de la máquina sea mínima, y que permitan la elevación de las placas y sus movimientos verticales de forma que sea máxima la adaptación de las mismas a las irregularidades del terreno (algunas máquinas permiten salvar obstáculos de $250 \mathrm{~mm}$ de altura).

La energía necesaria para el funcionamiento de la máquina es generada en el caso de la Vibrotek R 42, por un motor Diesel de 37,5 CV., refrigerado por aire, el cual está acoplado directamente a un alternador trifásico de $25 \mathrm{kVA}$ y por medio de una transmisión de correas trapezoidales a una bomba óleo-hidráulica.

El alternador genera la corriente necesaria para el funcionamiento de los electrovibradores, pudiendo ser empleado como equipo generador cuando la máquina no realice trabajos de compactación. 
Valores experimentales que muestran las características de compactación de un determinado modelo de compactadora de placas.

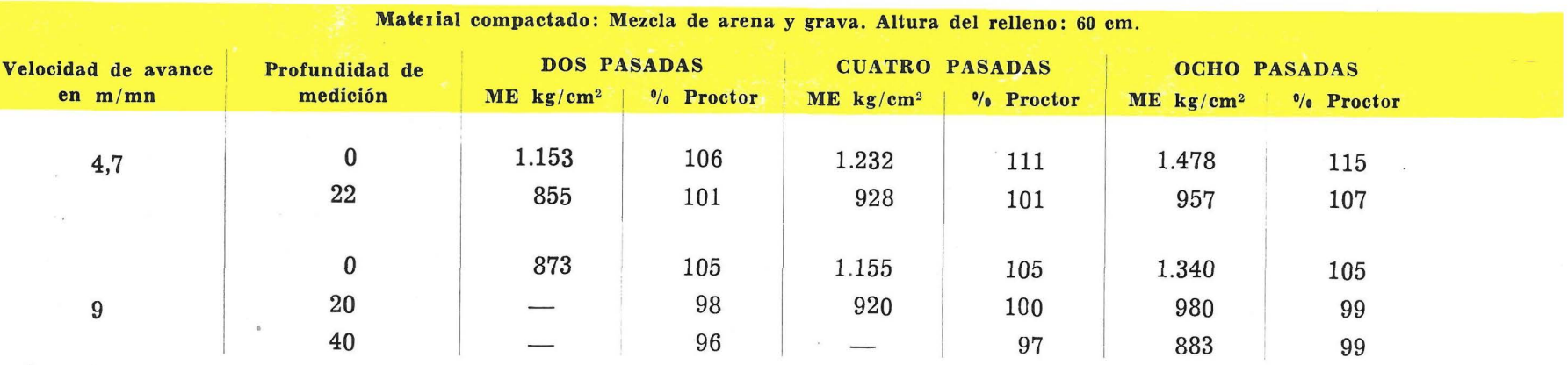

La bomba de aceite proporciona la presión necesaria para el sistema hidráulico, medio por el cual se efectúa el movimiento de avance de la máquina y la elevación de las placas compactadoras en grupos de dos o de tres, con el fin de lograr anchuras de trabajo variables.

Debido al accionamiento hidráulico del mecanismo de avance de la máquina, se consigue una progresiva regulación de las velocidades sin escalonamientos, y una fácil y rápida inversión de marcha.

El cuadro muestra que para arena, grava y $60 \mathrm{~cm}$ de relleno se obtuvieron casi los mismos resultados con un avance de $4,7 \mathrm{~m} / \mathrm{mn}$ y dos pasadas, que con $9 \mathrm{~m} / \mathrm{mn}$ de avance y cuatro pasadas.

La unidad está dotada de una caja de cambios de velocidades que permite conseguir velocidades de trabajo comprendidas entre los 0 y los 700 metros por hora, y velocidades de transporte entre 0 y $4 \mathrm{~km} / \mathrm{h}$. El accionamiento independiente de las orugas y la rápida inversión de marchas facilita la ejecución de giros.

La fuerza centrífuga puede regularse entre los 2.200 y los $4.200 \mathrm{~kg}$, siendo la frecuencia de 2.800 r.p.m.

Una sensible ventaja que presenta este tipo de máquinas compactadoras, sobre otros tipos más convencionales, es la facilidad de efectuar los trabajos de compactación en las partes exteriores del terraplén, ya que al sobresalir lateralmente de 60 a $100 \mathrm{~mm}$ los elementos compactadores de la base de sustentación de la máquina, se logran fácilmente ejecutar compactaciones perfectamente horizontales sobre el borde exterior.

M. CHINCHILLA
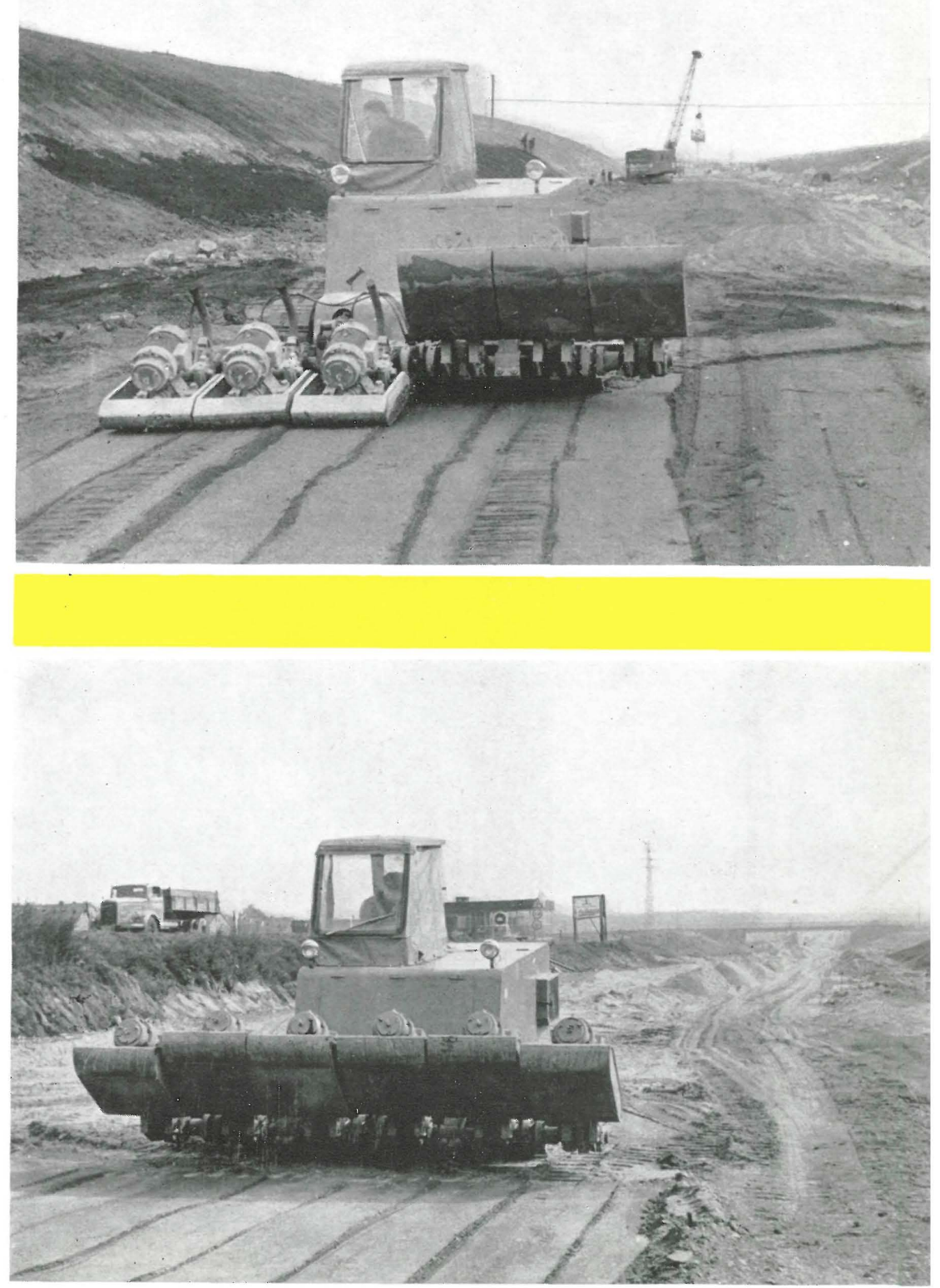